\title{
Childhood autism: its diagnosis, nature, and treatment
}

\author{
Sula Wolff
}

Leo Kanner, ${ }^{1}$ although not the first to describe this serious and intriguing developmental disorder of early childhood, ${ }^{2}$ so precisely captured its essential features that the clinical account of his first 11 cases has never been bettered. The salient characteristics he mentioned were an 'extreme autistic aloneness' from the beginning of life, delay and abnormality in language acquisition with echolalia and pronomial reversal, and 'an obsessional desire for the maintenance of sameness' in the presence of islets of normality, in particular an excellent rote memory. He saw the primary deficit as an inborn disturbance of affective contact and later described similar, although very mild features of emotional coldness and obsessionality in the parents.

Since then research into autism and related developmental disorders has flourished, there is a journal entirely devoted to them and, although they are so rare, their elucidation promises to shed light on many unanswered questions both about normal development of language and sociability and about the nature of a number of clinical conditions.

Recent growth areas of research have been the genetics of autism, the relation between autism and allied clinical syndromes, the nature of the psychological dysfunctions of autistic people, and the effects of specific treatment interventions. There have also been changes in how the condition is perceived and classified in the newer systems of diagnostic classification. Before reviewing recent progress, some basic facts must be recalled.

Age of onset, sex, social class incidence, prevalence, and prognosis

Though most cases, as Kanner himself noted, develop the disorder insidiously from birth, in some there is an early period of apparently normal social and language development followed by a set back. Autism is distinguished from other pervasive developmental disorders, as we shall see, by its onset before 30 to 36 months of age. More boys than girls are affected (a ratio of about 2·5-3:1). The sex ratio is more equal when autism is associated with organic brain disease or severe mental retardation. The social class distribution of families with autistic children has been found upwardly skewed in some studies, especially in well functioning autistic children, ${ }^{3}$ but not in others. ${ }^{4} \mathrm{~A}$ number of epidemiological prevalence studies have found two to four autistic children in every 10000 , more if severely retarded children with autistic features are included. ${ }^{2}$

There have been several long term follow up studies of autistic clinic attenders but only two of total population samples. ${ }^{5}$ Gillberg and Steffenburg followed up 23 autistic children and 23 with 'other psychoses', often associated with organic handicapping conditions, to the age of $16-23$ years. $^{6}$ In $17 \%$ of both groups outcome was 'good' or 'fair', and in $44 \%$ of autistic and $70 \%$ of other psychotic children it was 'poor' or 'very poor'. Among this still quite young group of subjects only one was self supporting, 23 lived with parents, 20 in institutions for the handicapped, and one in a psychiatric clinic. Altogether $35 \%$ of the total group (29\% of autistics) had developed epilepsy, 50\% between 13 and 14 years. One half had deteriorated symtomatically in early adolescence with no difference between the two groups. A perceptive observation was that, while as children the autistics were often particularly attractive to look at, after puberty their appearance tended to coarsen, often becoming clearly deviant. As in previous studies, the best predictors of outcome were a preschool measured intelligence quotient (IQ) of 50 or more and the presence of communicative speech before the age of 6 . Epilepsy and fragile $\mathrm{X}$ chromosome abnormality were associated with a worse outcome.

Although many early symptoms-echolalia, social withdrawal, and stereotypies-tend to disappear with age, severe social impairments and abnormalities of language use remain, and the overall outlook for autistic children is poor. Nevertheless, that minority whose intelligence is within the normal range can do surprisingly well despite serious childhood abnormalities. Szatmari et al found that among 16 autistic children with mean IQ of 92 , four had 'recovered' at a mean age of 26 years, living independent lives and with long term relationships. ${ }^{7}$ One had married. Eight in all were totally independent, six needed only minimal supervision, and seven had obtained university degrees. On the other hand, even among these rare well functioning autistics, one was profoundly retarded at follow up, one had chronic schizophrenia, three had hallucinations, and two paranoid thinking. Two were unemployed, three in sheltered workshops, and nine had never dated.

\author{
University De
of Psychiatry, \\ Royal Edinburgh \\ Hospital, \\ Morningside Park \\ Correspondence to: \\ Dr Wolff.
}


Diagnostic classification, diagnostic instruments, diagnostic criteria

The diagnostic criteria for autism have changed in emphasis over time ${ }^{8}$ as the condition has come to be viewed not so much as a psychosis specific to childhood, as in the International Classification of Diseases, 9th revision (ICD-9), ${ }^{9}$ but rather as a deviation of multiple developmental processes. This gave rise to the DSM-III (Diagnostic and Statistical Manual of Mental Disorders, 3rd edition) and DSM-III-R (revised edition) concept of 'pervasive developmental disorder' 1011 and contributed to the envisaged changes for ICD-10. ${ }^{12}$ Here too autism is classified as a pervasive developmental disorder. This concept, like that of the specific developmental disorders, ${ }^{12}$ involves an onset very early in life, impairment of functions related to biological maturation, a steady course without appreciable remissions and relapses, improvement with age, an increased incidence in males, and an often familial association with similar or related disorders. This concept has justly been criticised as not in itself logical nor fully applicable to childhood autism ${ }^{13}$ (autism does not affect all developmental areas, its course is not always steady from birth and, while symptoms change over time, only a few cases improve with maturation). The diagnostic criteria for autism itself, however, are clear and there is good evidence for their validity. ${ }^{8} \mathrm{~A}$ detailed autism diagnostic observation schedule and an autism diagnostic interview of excellent reliability and validity, have recently been developed for research purposes by an international research group. ${ }^{14}$ is

The diagnosis of autistic disorders, as they are now called, rests on three main groups of symptoms:

(1) Qualitative impairment and deviance of reciprocal social relationships with abnormalities of gaze and social responsiveness to other people, especially other children.

(2) Deviant development of language and other communication skills, with either no language at all, early onset followed by loss of speech, or delayed onset and characteristic language features such as immediate and delayed echolalia, pronomial reversal, metaphorical expressions and, especially, a failure in language use (in the 'pragmatics' of language), relative to available comprehension and language skills.

(3) Repetitive, stereotyped patterns of behaviour, which include Kanner's 'obsessive desire for the maintenance of sameness', but also prolonged attachments to particular objects, the formation of rows of toys irrespective of the needs of the rest of the household, extreme food fads, repetitive questioning often with insistence on ritualistic 'to and fros' with others, and motor stereotypies.

While age of onset distinguishes well between autistic disorders and early onset schizophrenia, which rarely begins before puberty, childhood disintegrative disorders as they are to be called in ICD-10 (the former disintegrative psychoses) tend to manifest only after the age of 3 and autism usually before 30 months. In this classification age of onset, the fourth criterion, has been set to under 3 years to improve differentiation from disintegrative disorders with their much poorer prognosis (DSM-III-R, still uses the 30 months cut off between early and 'late onset' autism).

\section{Differential diagnosis: the borderlands of} autism

Half of severely retarded children (IQ less than 50) have symptoms of autism. ${ }^{16}$ Although their educational and treatment needs resemble those of autistic children and they need much one to one teaching to compensate for their social unresponsiveness, for research purposes a clear distinction must be made. For research and practice it is also important to differentiate autistic children from those rare cases of disintegrative disorder after a period of at least three years of apparently normal development. While the aetiology of this condition generally remains unknown, it may be caused by progressive, degenerative brain disease such as cerebral lipoidosis or leucodystrophy. The end state is usually one of severe mental handicap with no available language. Rett's syndrome may be symptomatically indistinguishable from autism because of its early onset, but occurs predominantly in girls and is associated with normal prenatal and perinatal development. Rett's syndrome is also distinguishable by a decrease in head growth after 5 months of age, loss of hand skills between 6 and 30 months, and increasing gait and trunk apraxia and ataxia. ${ }^{17}$ Doubt has recently been cast on the assumption that the fragile X chromosome abnormality, perhaps the second most common cause of mental retardation, is also specifically linked to autism. Payton et al found a $2.4 \%$ incidence of this abnormality in 85 autistic males, similar to that in a mentally retarded male population. ${ }^{18}$

The differential diagnosis of autism from schizophrenia, specific developmental language disorders, and Asperger's syndrome (also referred to as schizoid or schizotypal personality disorder) is less problematical in clinical practice, but raises many aetiological issues to be discussed next.

\section{Aetiology}

Goodman has clearly summarised the arguments in favour of multiple coexisting factors in the causation of autism, although he does not make the point that the condition may be so rare because it requires the coincidence of more than one, perhaps quite common, causal agents. ${ }^{19}$ Goodman focuses especially on the coexistence of distinct constellations of functional impairments necessary for autism: impairments of general intelligence, deficits in mechanical language skills, as in the developmental dysphasias, and deficits in social relatedness, play and non-verbal communication as in Asperger's syndrome. A difficulty here is that a number of children with specific developmental language disorders also have social deficits resembling those of Asperger/schizoid/schizotypal disorders, ${ }^{20}$ and almost half the boys with these disorders had serious or multiple specific developmental delays of language related skills (S Wolff, unpublished observations). 
Two types of causal agents have been identified: those associated with brain damage and genetic factors. It is known that autistic children have somewhat higher rates of paranatal abnormalities and that they are prone to develop epilepsy, not so much in infancy and early childhood as are mentally retarded and severely birth injured children, but in early adolescence. In a minority of cases there is a specific association with some types of cerebral disorder and not with others (with congenital rubella and tuberous sclerosis for example, but not with Down's syndrome or cerebral palsy). ${ }^{2}$ Moreover, when monozygotic twins are discordant for autism, it is the autistic twin who more often had evidence of paranatal injury.

There have been three population based twin studies of autism: two in the UK, including a follow up of one set of twins into adult life, and one in Scandinavia (A LeCouteur, et al; paper presented at First World Congress on Psychiatric Genetics, Cambridge, 1989). ${ }^{21}{ }^{22}$ The concordance rate for autism itself in monozygotic pairs ranged from 36 to $91 \%$ and in dizygotic pairs from 0 to $10 \%$. The concordance rates for other cognitive and social impairments, including global and specific developmental delays and deficient or unusual social responsiveness (which tended to get worse with age), ranged from 82 to $91 \%$ in monozygotic pairs and from 0 to $30 \%$ in dizygotic pairs. Clearly, what is inherited is either the full syndrome or a lesser variant consisting of both cognitive and social impairments.

Further evidence for this comes from the studies of siblings and other biological relatives of autistic children. The evidence, still requiring confirmation, is of an excess of cognitive delays among the siblings of severely retarded autistic children, and an excess of minor social impairments of the Asperger/schizoid/schizotypal kind in the parents and other biological relatives of high functioning autistics. ${ }^{23}{ }^{24}$ Piven et al found an excess of autism (3\%), of 'severe social dysfunction and isolation' $(4 \cdot 4 \%)$, and of cognitive disorders (15\%) in adult siblings of autistic children, especially in those who had been diagnosed by Kanner himself. ${ }^{25}$

There is no excess of schizophrenia in the biological relatives of autistics and no excess of the much rarer condition of autism in the relatives of schizophrenics. The two conditions are clinically distinct in their symptomatology, age of onset, sex, and social class distributions and associations with mental retardation and epilepsy. ${ }^{26}$ They may nevertheless share a genetic predisposition to the schizophrenia spectrum disorders of the Asperger/schizoid/schizotypal kind. Altogether $75 \%$ of children diagnosed 'schizoid' have the features of schizotypal personality disorder in adult life and this is firmly part of the schizophrenia spectrum (S Wolff et al, unpublished observations). The symptoms of such children: solitariness, lack of empathy, the single minded pursuit of special interest patterns, unusual modes of communication, and oversensitivity, although different, resemble those of autism in that they are all features of deficits in social and emotional relationships with other people and in communication skills, together with single minded pursuits of particular interests or behaviours. There have also been a few case reports of families with both an autistic child and a child with Asperger's syndrome, and series of cases have been reported in which a very early onset of schizophrenia was preceded by a clear cut autistic syndrome. ${ }^{27}$

Autism is likely to be a heterogeneous condition, with different causal factors operating in different groups of cases. ${ }^{21}$ In a very few the clinical syndrome is associated with chromosomal or single gene abnormalities: fragile $\mathrm{X}$ chromosome, phenylketonuria, tuberous sclerosis, or neurofibromatosis; in others with infections: congenital rubella; and in yet others with evidence of diffuse brain dysfunction. Although symptomatically similar, severely mentally handicapped and well functioning autistic people may differ in the causal agents and pathologies involved. The genetic basis too may differ in different groups of cases and may involve single or multiple genes.

So far, while brain lesions have increasingiy been found with the newer technologies in autistic children, no consistent pattern has emerged and children with and without such lesions do not differ symptomatically. ${ }^{28}$ No specific metabolic abnormalities have been identified. High serotonin concentrations have been found in one third of autistic children, but also in severely retarded non-autistic children, ${ }^{29}$ and the results of treatment with fenfluramine to counteract such high concentrations have been equivocal.

\section{The nature of the deficits}

The early work of Hermelin and O'Connor, in which psychological functioning of autistics was compared with that of IQ matched retarded and normal children, showed impaired encoding and restructuring of information. ${ }^{30}$ Although short term memory, for example for random words, was normal, the memory of autistics unlike that of controls did not improve for word sequences with meaning. Autistic children could not use redundancy to improve their memory span. Moreover, their language deficit was but one aspect of a more general inability to use signs and symbols, and they were better at processing spatial than temporal sequences; this is in line with their often remarkable jigsaw solving skills.

Since then there have been a number of imaginative explorations of the autistic child's specific functional disabilities. Peter Hobson, again comparing autistic with normal and mentally retarded subjects, examined their capacity to match videos of people's vocalisation, facial expression, and activities associated with those emotions that have clear cut facial expressions (anger, fear, happiness, and sadness) against photographs and line drawings of faces or activities expressing these same emotions. ${ }^{31} \mathrm{He}$ found autistics specifically impaired in the recognition of vocalisations and facial expressions of emotions. Even as adults autistic people are deficient both in the recognition and expression of emotions verbally (that is, in their tone of voice) and facially. ${ }^{32}$ Hobson believes that the basic 
flaw in autism is in the biologically based capacity, normally present in everyone, for attention and empathic responsiveness to the emotional expression and emotional behaviour of others.

Simon Baron-Cohen ${ }^{33}$ and Uta Frith ${ }^{34}$ see these difficulties as part of a more general cognitive deficit: an impairment in the capacity to infer what is in the minds of others-that is, a lack of a 'theory of mind'. In one of a series of imaginative experiments autistic, Down's syndrome, and normal children were shown two dolls, one with a basket and one with a box. The first doll puts some marbles in her basket and goes out. The second then takes the marbles from the basket and puts them in her box. The first doll returns, and the question to the experimental child is: where does the first doll look for the marbles? The autistic children tend to answer: in the box, because that is where they known the marbles to be. Other children of similar IQ can put themselves into the 'mind' of doll number one, know that this doll is unaware of the transfer of marbles, and correctly point to the basket as the container first to be explored. Frith sees autistic individuals as 'natural behaviourists', who do not feel the normal compulsion to weave together mind and behaviour for the sake of coherence.

Baron-Cohen believes the primary defect in autism to be cognitive; Hobson sees it as primarily emotional. Yet both sociability and prelinguistic behaviour develop together towards the end of the first year of life and, though linguistic-cognitive and emotional abilities are often selectively impaired (for example, in the retarded or in children with specific developmental delays), there is no reason why these two types of functions, so intimately connected in the development of the baby, should not be impaired together. Frith makes clear that the specific autistic impairments, which include also the absence of make believe play, of role modelling, and an inability to distinguish pretence play from reality, all involve competencies which normally begin to develop in the second year of life. This is also the time at which correct empathic responses to distress in others are first seen and is precisely the time at which the symptoms of autism first become apparent. Although the basic defect is likely to be inborn, it does not manifest until the time at which the impaired functions normally appear.

\section{Treatment approaches}

There have been two excellent controlled studies of treatment interventions for autistic children, one now a classic, ${ }^{35}{ }^{36}$ the other more recent. ${ }^{37}$ The first demonstrated clearly the superiority of a structured, behaviourally oriented teaching approach geared to the child's particular developmental level, and with much one to one teaching and contingent reinforcements. The children progressed more both educationally and socially, with less repetitive stereotyped behaviour in free play settings, than children at schools where a permissive approach was emphasised and the focus was on responding to possible underlying emotional problems. Even with the most effective methods, however, no child with an IQ below 50 gained useful skills in literacy or numeracy.

The more recent study by Howlin and Rutter of the efficacy of an intensive, home based, behaviourally oriented intervention has been reported in a book that has much to teach all clinicians who look after autistic children, because it focuses also on the problems of parents and the other children in affected families. ${ }^{37}$ It makes clear that, whatever the specific technical interventions, families with an autistic child are coping with particularly stressful circumstances and require skilled counselling in their own right. Such families need informed recommendations for special schooling for the child, and social work services providing access to facilities for respite care, holidays, financial entitlements, and special, often residential, settings for the autistic person at and after adolescence. Due emphasis is given to the practical help and emotional support that can come from joining the National Autistic Society or one of its local equivalent organisations.

As for the specific treatment interventions, they were individually tailored to the needs of each autistic child and family, with highly specific treatment goals. The focus was on fostering the development of language, play, and social interactions. Treatment also aimed to decrease the specific obsessional, ritualistic behaviour of the autistic children, and to help parents reduce their children's often so distressing general behavioural difficulties such as sleep and elimination disorders, food fads, temper tantrums, and screaming attacks. Parents were the therapists, but care was taken not to impose too time consuming a programme on them. While behavioural techniques of operant learning with prompting, fading, reinforcement procedures and 'time out', if necessary, were taught to the mothers by demonstration in their homes after a full functional analysis of the child's behaviour, the approach to the families as a whole used psychotherapeutic methods also.

In this study treated children (all with an IQ of 60 or more and without associated medical conditions) were compared with matched control groups both for short term gains (at six months) and for long term outcome (at 18 months). In the short term, the greatest improvement was in reducing the children's general disruptive behaviour and their ritualistic and other solitary activities. The overall level of language usage also improved significantly, with reduction of echolalia and stereotyped utterances, but there was little difference in the level of language complexity between treated and control groups, both of which improved over time. Mothers of children just on the threshold of speech were best able to put what they were taught into practice, presumably because their children were the most rewarding to teach. In the long term, treatment worked best for general disorders such as temper tantrums, aggression, sleep and toiletting difficulties; it also reduced but never totally removed specific autistic rituals and routines. Play and social behaviour was also improved relative to the controls but always remained severely restricted. The communicative use of language, 
but not language competence, improved also, but there was no difference at all in the overall level of cognitive capacity. The authors caution that all treatment approaches need to be so structured that the demands on the parents are reduced rather than increased, but also that, to avoid disppointment and frustration, treatment goals must be realistic. The results of this well controlled study will certainly contribute to this. The study also demonstrates that without adequate controls new treatments can all too easily engender false hopes.

There has recently been much publicity for 'holding therapy'. While this emotionally exhausting method may well lead to some increase in emotional contact between the autistic child and the 'holding' parents immediately after the session, there have been no properly controlled outcome studies to back up the often extravagant claims for the efficacy of this method.

What is clear, in the management of autistic children and their families, is first the need for all affected children to be diagnosed and for possible associated neurological or genetic abnormalities to be identified. Whether or not such pathologies exist, all autistic children should be notified to the educational services so that they can benefit from the special educational arrangements they need and which are increasingly available in the $\mathrm{UK}$ as a result of local authority endeavours and the resources established by the parent societies for autistic children. Second, all families with autistic children need long term care and support to ensure their access to all the treatment and back up services they may need as the child grows up. These include intensive, home based specific behavioural treatment approaches as outlined by Howlin and Rutter for those children likely to respond ${ }^{37}$; short term medication with major tranquillisers to cope with particularly distressing episodes of behaviour problems; and an understanding of the possible personality and marital difficulties of the parents and of the stresses on the siblings of the autistic child with appropriate support and counselling. It is also important to have social work help to ensure the families have access to their financial entitlements and to holiday and other respite services and more intensive back up at adolescence when many autistic children will require day or residential units designed for their particular needs. Autistic children cannot generally benefit from work training centres set up for non-autistic handicapped young people. The National Autistic Society and other locally based parent societies for autistic people have contributed much in the setting up of special schools and adult units and in offering mutual support services for parents.

1 Kanner L. Autistic disturbances of affective contact. The Nervous Child 1943;2:217-50.

2 Rutter M. Infantile autism and other pervasive developmental disorders. In: Rutter M, Hersov L, eds. Child and adolescent psychiatry: modern approaches. Oxford: Blackwell 1985:545-66.

3 Lotter V. Epidemiology of autistic conditions in young children II: some characteristics of the parents and children. Soc Psychiatry 1967;1:163-73.

4 Gillberg C, Schauman H. Social class and autism: total population aspects. I Autism Dev Disord 1982;12:223-8.

5 Lotter V. Social adjustment and placement of autistic children in Middlesex: a follow-up study. Fournal of Autism and Childhood Schizophrenia 1974;4:11-32.

6 Gillberg C, Steffenburg S. Outcome and prognostic factors in infantile autism and similar conditions: a population-based study of 46 cases followed through puberty. $\mathcal{F}$ Autism Dev Disord 1987;17:273-87.

7 Szatmari P, Bartolucci G, Bremner R, Bond S, Rich S. A follow-up study of high-functioning autistic children. A follow-up study of high-functioning

8 Rutter M, Schopler E. Autism and pervasive developmental disorders: concepts and diagnostic issues. $\mathcal{J}$ Autism Dev
, Disord 1987;17:159-86

9 World Health Organisation. International classification of diseases. 9th Revision. Geneva: WHO, 1978.

10 American Psychiatric Association. Diagnostic and statistical manual of mental disorders (DSM-III). 3rd Ed. Washington, DC: American Psychiatric Association. 1980.

11 American Psychiatric Association. Diagnostic and statistical manual of mental disorders (DSM-III-R). 3rd Ed revised.
Washington, DC: American Psychiatric Association, 1987.

Rutter M. Child psychiatric disorders in ICD-10. F Child Psychol Psychiatry 1989;30:499-513.

13 Gillberg C. Autism and pervasive developmental disorders. Annual Research Review. $\mathcal{J}$ Child Psychol Psychiatry 1990; 31:99-120.

14 LeCouteur A, Rutter M, Lord C, et al. Autism diagnostic interview: a standardized investigator-based instrument. f Autism Dev Disord 1989;19:363-87.

15 Lord C, Rutter M, Goode S, et al. Autism diagnostic observation schedule: a standardized observation of communicative and social behavior. $\mathcal{F}$ Autism Dev Disord 1989;19:185-212.

16 Wing $L$. Language, social and cognitive impairments in autism and severe mental retardation. $\mathcal{F}$ Autism Dev Disord 1981;11:31-44.

17 Gillberg C. The borderland of autism and Rett syndrome: 5 case histories to highlight diagnostic difficulties. F Autism Dev Disord 1989;19:545-59.

18 Payton JB, Steele MW, Wenger SL, Minshaw NJ. The fragile $\mathrm{X}$ male and autism in perspective. $\mathcal{F} \mathrm{Am}$ Acad Child Adolesc Psychiatry 1989;28:417-21.

19 Goodman $R$. Infantile autism: a syndrome of multiple primary deficits. I Autism Dev Disord 1989;19:409-24.

20 Cantwell DP, Baker L, Rutter M, Mahood L. Infantile autism and developmental receptive dysphasia: a comparative follow-up into middle childhood. $\mathcal{F}$ Autism Dev Disord 1989;19:19-31.

21 Folstein S, Rutter M. Autism: familial aggregation and genetic implications. $\mathcal{f}$ Autism Dev Disord 1988;18:3-30.

22 Steffenburg S, Gillberg C, Hellgren L, et al. A twin study of autism in Denmark, Finland, Iceland, Norway and Sweden. F Child Psychol Psychiatry 1989;30:405-16.

23 Wolff S, Narayan S, Moyes B. Personality characteristics of parents of autistic children: a controlled study. $\mathcal{f}$ Child Psychol Psychiatry 1988;29:143-53.

24 Narayan S, Moyes B, Wolff S. Family characteristics of autistic children: a further report. F Autism Dev Disord 1990;20: 523-35.

25 Piven J, Gayle J, Chase GA, et al. A family history study of neuropsychiatric disorders in the adult siblings of autistic neuropsychiatric disorders in the adult siblings of autistic
individuals. $\mathcal{I}$ Am Acad Child Adolesc Psychiatry 1989;29: individuals.

26 Kolvin I. Psychoses in childhood-a comparative study. In: Rutter M, ed. Infantile autism: concepts, characteristics and treatment, London: Churchill Livingstone, 1971:7-26.

27 Watkins JM, Asarnow RF, Tanguay PE. Symptom development in childhood onset schizophrenia. F Child Psychol Psychiatry 1988;29:865-78.

28 DeLong GR, Bauman ML. Brain lesions in autism. In: Schopler E, Mesibov GB, eds. Neurobiological issues in autism. New York: Plenum, 1987:229-42.

29 LeCouteur A, Trygstad O, Evered C, Gillberg C, Rutter M. Infantile autism and urinary excretion of peptides and protein-associated peptide complexes. 7 Autism Dev Disord 1988;18:181-90.

30 Hermelin B, O'Connor N. Psychological experiments with autistic children. London: Pergamon, 1970.

31 Hobson RP. Beyond cognition: a theory of autism. In: Dawson G, ed. Autism: nature, diagnosis, and treatment. Dawson G, ed. Autism: nature, diag

32 Macdonald $H$, Rutter $M$, Howlin $P$, et al. Recognition and expression of emotional cues by autistic and normal adults. foxpression of emotional cues by autistic and

33 Baron-Cohen S. Social and pragmatic deficits in autism: cognitive or affective? $\mathcal{J}$ Autism Dev Disord 1988;18: $379-402$.

34 Frith U. Autism: explaining the enigma. Oxford: Blackwell, 1989.

35 Bartak L, Rutter M. Special educational treatment of autistic children: a controlled study. I: Design of study and characteristics of units. $\mathcal{F}$ Child Psychol Psychiatry 1973;14: 161-79.

36 Rutter M, Bartak L. Special educational treatment of autistic children: a controlled study. II: Follow-up findings and implications for services. $\mathcal{F}$ Child Psychol Psychiatry 1973; 14:241-70.

37 Howlin P, Rutter M. Treatment of autistic children. London: Wiley, 1987. 